\title{
Application of Taguchi Method for Optimization of Process Parameters in Drilling Operation
}

\author{
R. Manohara1, Mr. A. Harinath² \\ 1P.G Scholar, ${ }^{2}$ Assistant Professor \\ 1,2Department of mechanical engineering, \\ 1,2Sri Venkateswara institute of technology, Anantapur, Andhra Pradesh, India
}

\begin{abstract}
How to cite this paper: R. Manohara | Mr. A. Harinath "Application of Taguchi Method for Optimization of Process Parameters in Drilling Operation" Published in International Journal of Trend in Scientific Research and Development (ijtsrd), ISSN: 24566470, Volume-3 | Issue-4, June 2019, pp.1052-1057, URL: https://www.ijtsrd.c om/papers/ijtsrd24

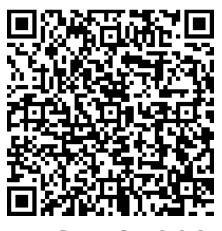
IITSRD24003
\end{abstract} 003.pdf

Copyright (C) 2019 by author(s) and International Journal of Trend in Scientific Research and Development Journal. This is an Open Access article distributed under the terms of the Creative Commons

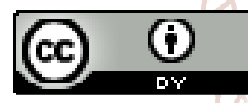
Attribution License (CC BY 4.0) (http://creativecommons.org/licenses/ by $/ 4.0$ )

later its application was expanded to many other fields in Engineering, such as Biotechnology etc. Professional statisticians have acknowledged Taguchi's efforts especially in the development of designs for studying variation. Success in achieving the desired results involves a careful selection of process parameters and bifurcating them into control and noise factors.

Selection of control factors must be made such that it nullifies the effect of noise factors. Taguchi Method involves identification of proper control factors to obtain the optimum results of the process. Orthogonal Arrays (OA) are used to conduct a set of experiments. Results of these experiments are used to analyze the data and predict the quality of components produced.

Here, an attempt has been made to demonstrate the application of Taguchi's Method to improve the surface finish characteristics of faced components that were processed on a lathe machine. Surface roughness is a measure of the smoothness of a products surface and it is a factor that has a high influence on the manufacturing cost. Surface finish also affects the life of any product and hence it is desirable to obtain higher grades of surface finish at minimum cost.

\section{APPROACH TO PRODUCT/PROCESS DEVELOPMENT}

Many methods have been developed and implemented over the years to optimize the manufacturing processes. Some of the widely used approaches are as given below:

\section{Build-Test-Fix}

The "Build-test-fix" is the most primitive approach which is rather inaccurate as the process is carried out according to the resources available, instead of trying to optimize it. In this method the process/product is tested and reworked each time till the results are acceptable.

\section{$>$ One Factor at a Time}

The "one-factor-at-a-time" approach is aimed at optimizing the process by running an experiment at one particular condition and repeating the experiment by changing any other one factor till the effect of all factors are recorded and analyzed. Evidently, it is a very time consuming and expensive approach. In this process, interactions between factors are not taken in to account.

$>$ Design of Experiments Application of Taguchi Method for Optimization of Process Parameters in Improving the Surface

Conventional machining in which a sharp cutting tool is used to mechanical cut the material to achieve the desired shape, 
size and geometry. The predominant cutting action in machining involves shear deformation of the work material to form a various kinds of chips; as the chips removed, a new surface is exposed, that is called as machined surface. Machining is a most frequently applied to shape metals.

\section{DRILLING MACHINE}

Drilling is a most common and complex used industrial machining processes of creating and originating a hole in mechanical components and work piece. The tool used, called a drill and the machine tool used is called a drill machine.

Drilling can also be define as a rotary end-cutting tool having one or more cutting edges called lips, and having one or more helical or straight flutes for the passage of chips and passing the cutting fluid to the machining zone.

Rotating drill fed into the stationary work piece to form a hole whose diameter is determined by the drill diameter. Drilling makes up about 25\% of all the machining processes performed. Drilling is really a Complex Process, because Only exit for the chips is the hole that filled by the drill. Friction results in heat in addition to that due to chip. Counter flow of chips makes lubrication and cooling difficult.

\section{KINEMATIC SYSTEM OF GENERAL PURPOSE DRILLING MACHINE AND THEIR PRINCIPLE OF WORKING}

Kinematic system in any machine tool is comprised of chain of several mechanisms to enable transform and transmit motion from the power source to the cutting tool and the work piece for the desired machining action.

The kinematic structure varies from machine tool to machine tool requiring different type and number of tool-work motions. Even for the same type of machine tool, say column drilling machine, the designer may take different kinematic structure depending upon productivity, process capability, durability, compactness, overall cost etc targeted. Typical kinematic system of a very general-purpose drilling machine are, a column-drilling machine having 12 spindle speeds and 6 feeds. The kinematic system enables the drilling machine the following essential works as:

Cutting Motion

Feed Motion

Tool Work Mounting

\section{TWIST DRILLS}

Drill bits are cutting tools used to create cylindrical holes. Bits held in a tool called a drill, which rotates them and provides torque and axial force to create the hole. Different point angle drills and different diameter drills and of different length of drills can be used according to the application of work.

\section{LITERATURE REVIEW}

Gaitonde, Karnik and Davim carried out study on drilling of LAMIPAN PB (wood coating layer) Medium Density Fibre board panel using cutting conditions i.e. spindle speed $\&$ feed rate to minimize the delamination tendency Using Response Surface Methodology and Taguchi Design \& by forming L9 Orthogonal Array on $16 \mathrm{~mm}$ thickness panel and $5 \mathrm{~mm}$ diameter panel. Cemented Carbide drills (K20 grade, 20 helix and $60^{\circ}$ point angle) were, employed for the experimentation. Result of Response surface analysis clearly indicates it is necessary to employ low values of feed rate along with the higher values of cutting speed.

\section{METHODOLOGY OBJECTIVE OF THE PRESENT WORK}

The objective of the present work is to find out main effect of cutting speed, feed rate, drill diameters, work piece material, drill material and interaction effect between drill material and cutting speed on MRR, Surface roughness, Hole diameter error, and burr height. Microstructure analysis of work piece material also did. The formula used for measuring the MRR are given below

$$
\begin{aligned}
& \text { MRR is given by: } \\
& M R R=(W i-W f) / \operatorname{tgm}^{3} / \mathrm{min}
\end{aligned}
$$

$\mathrm{W}_{\mathrm{i}}=$ Initial weight of work piece material in gram $\mathrm{W}_{\mathrm{f}}=$ Final weight of work piece material in gram $\mathrm{t}=$ Time period of machining in minutes

\section{DEGREES OF FREEDOM (DOF)}

Total degree of freedom required for the entire experimentation determined by the number of factors, their interactions effects and level for factors. The degree of freedom for each factor is given by the number of levels minus one.

DOF for each factor $=\mathrm{k}-1$

Where $\mathrm{k}$ is the number of level for each factor

DOF for interactions between factors: $\left(\mathrm{k}_{\mathrm{A}}-1\right) \times\left(\mathrm{k}_{\mathrm{B}}-1\right)$ Where $\mathrm{k}_{\mathrm{A}}$ and $\mathrm{k}_{\mathrm{B}}$ are number of level for factor $\mathrm{A}$ and $\mathrm{B}$

\section{ORTHOGONAL ARRAY}

OA derived from factorial design of experiment by a series of very sophisticated mathematical algorithms including combinatory, finite fields, geometry and error correcting codes. OA plays a critical part in achieving the high efficiency of the Taguchi method. The OA is constructed in a statistically independent manner Within each column, number of occurrences of each level is equal and for each level within one column, each level within any other column will occur an equal number of times as well.

Then, the columns are called orthogonal to each other. OA is available with a variety of factors and levels in the Taguchi method. Since each column is orthogonal to the others, if the results associated with one level of a specific factor are much different at another level, it is because changing that factor from one level to the next has strong impact on the quality characteristic being measured. Since the levels of the other factors are occurring an equal number of times for each level of the strong factor, any effect by these other factors will be ruled out. The selection of orthogonal array will depend on: $>$ The number of factors and interactions of interest

$>$ The number of levels for the factors of interest

Taguchi orthogonal arrays are experimental designs that usually require only a fraction of the full factorial combinations. The columns of arrays are balanced and orthogonal. This means that in each pair of columns, all factor combinations occur same number of times. Orthogonal designs allow estimating the effect of each factor on the response independently of all other factors. Once the degrees of freedom are known, the next step is to select the orthogonal array (OA). The number of treatment conditions is equal to the number of rows in the orthogonal array and it must be equal to or greater than the total degrees of freedom. Once the appropriate orthogonal array has been selected, the factor can be assigned to the various columns . L18 Linear graph is shown in figure that's used in experiment and experimental design of L18 is shown in Table. 
Table 1: L18 Experimental design

\begin{tabular}{|c|c|c|c|c|c|}
\hline Trial no & Tool material & Cutting speed (RPM) & Feed (mm/rev) & Drill diameter (mm) & Work-piece material \\
\hline
\end{tabular}

\begin{tabular}{|c|c|c|c|c|c|}
\hline 1 & M2 HSS & 80 & 0.10 & 4 & EN 31 \\
\hline 2 & M2 HSS & 80 & 0.125 & 8 & H 11 \\
\hline 3 & M2 HSS & 80 & 0.150 & 12 & $\mathrm{HCHCr}$ \\
\hline 4 & M2 HSS & 160 & 0.10 & 4 & H 11 \\
\hline 5 & M2 HSS & 160 & 0.125 & 8 & $\mathrm{HCHCr}$ \\
\hline 6 & M2 HSS & 160 & 0.150 & 12 & EN 31 \\
\hline 7 & M2 HSS & 244 & 0.10 & 8 & EN 31 \\
\hline 8 & M2 HSS & 244 & 0.125 & 12 & H 11 \\
\hline 9 & M2 HSS & 244 & 0.150 & 4 & $\mathrm{HCHCr}$ \\
\hline 10 & M35 HSS & 80 & 0.10 & 12 & $\mathrm{HCHCr}$ \\
\hline 11 & M35 HSS & 80 & 0.125 & 4 & EN 31 \\
\hline 12 & M35 HSS & 80 & 0.150 & 8 & H 11 \\
\hline 13 & M35 HSS & 160 & 0.10 & 8 & $\mathrm{HCHCr}$ \\
\hline 14 & M35 HSS & 160 & 0.125 & 12 & EN 31 \\
\hline 15 & M35 HSS & 160 & 0.150 & 4 & H 11 \\
\hline 16 & M35 HSS & 244 & 0.10 & 12 & H 11 \\
\hline 17 & M35 HSS & 244 & 0.125 & 4 & $\mathrm{HCHCr}$ \\
\hline 18 & M35 HSS & 244 & 0.150 & 8 & EN 31 \\
\hline
\end{tabular}

\section{EXPERIMENTAL SET UP}

The experiments have been conducted on Radial drilling machine shown in (Figure 3.2) available in the Machine Tool lab. Many input parameters like work piece material, cutting speed, feed, drill diameter and drill material has been varied in this experiment. Each factors has its own effect on the output parameters such as Material removal rate (MRR), Surface roughness (SR), hole diameter error and burr height. The input parameters, which kept constant during the experimentation, are given in the Table 3.4 Before start of experiment, the work piece material ground to remove any dust, durt particles or removing any surface defect and tapering effect of work piece.

Table 2: Constant input parameters for a drilling machine

\begin{tabular}{|c|c|c|}
\hline Sr. No. & Parameters & Value \\
\hline 1 & Machining time & $60 \mathrm{sec}$ \\
\hline 2 & Point angle & $118^{\circ}$ \\
\hline 3 & Helix angle & $32^{\circ}$ \\
\hline 4 & Shank type & Cylindrical \\
\hline 5 & No of flutes & 2 \\
\hline
\end{tabular}

\section{MEASURING AND TESTING EQUIPMENT USED}

Surface roughness tests conducted on all the 18 samples produced by the radial drilling machine. MRR was measured using an electric balance weighing machine which has a resolution of $0.01 \mathrm{mg}$, whereas Burr height was measured using a digital Calliper which has a resolution of $0.01 \mathrm{~mm}$. The details of important equipment used for the test in the experimental study are given below.

\section{Surface Roughness Tester}

Surface roughness test of all the samples measured by contact type stylus Model. The accuracy of this device is $0.01 \mu$ m. To measure the surface roughness, the blocks were sliced to the holes axes. The surface roughness was measured parallel to each hole axis and the average values of the surface roughness is taken.

The tools measuring surface roughness with probes, measure, and control in appropriate length and circumference the probe comes in and out holes while traveling on the surface. This movement is turned into electrical current by means of a coil or crystal. After increasing the current by using suitable units, its value is shown with a pointer or digitally.

\section{METHODOLOGY}

The Taguchi methodology is one of the optimizing techniques that based on the design of experiments (DOE) approach. The experiments analysis will propose to conduct using the design of experiments technique. Although full factorial designs can be use where in all the possible combinations can be test, we would use fractional factorial analysis methods for the experiment.

The Taguchi Design is a design of experiment (DOE) approach developed by Dr. Genichi Taguchi in order to improve the quality of manufactured goods in Japan. Although similar to factorial design of experiment, the Taguchi design only conducts balanced(orthogonal) experimental combinations, which makes the Taguchi design even more efficient than a fractional factorial design. The Taguchi methodology has been proposed to overcome the limitations of full factorial analysis by simplifying and standardizing the fractional factorial design . 


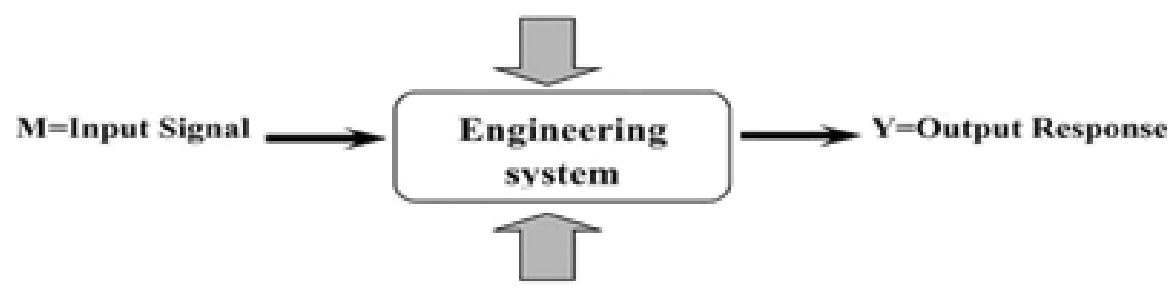

Noise Factors

Figure 1 the system (a) ideal function (b) the real system

Table: 3 Result for Surface roughness

\begin{tabular}{|c|c|c|c|c|c|c|c|c|c|}
\hline \multirow{2}{*}{$\begin{array}{c}\text { Trial } \\
\text { No }\end{array}$} & \multirow{2}{*}{$\begin{array}{c}\text { Tool } \\
\text { Material }\end{array}$} & \multirow{2}{*}{$\begin{array}{l}\text { Speed } \\
\text { (RPM) }\end{array}$} & \multirow{2}{*}{$\begin{array}{c}\text { Feed } \\
(\mathrm{mm} / \mathrm{rev})\end{array}$} & \multirow{2}{*}{$\begin{array}{c}\text { Drill } \\
\text { Diameter } \\
(\mathrm{mm})\end{array}$} & \multirow{2}{*}{$\begin{array}{l}\text { Work- } \\
\text { Piece }\end{array}$} & \multicolumn{2}{|c|}{$\begin{array}{c}\text { Surface } \\
\text { Roughness }(\mu \mathrm{m}) \\
\end{array}$} & \multirow{2}{*}{$\begin{array}{l}\text { Mean Surface } \\
\text { roughness }(\mu \mathrm{m})\end{array}$} & \multirow[t]{2}{*}{ S/N Ratio } \\
\hline & & & & & & I & II & & \\
\hline 1 & M2 & 80 & 0.10 & 4 & EN 31 & 0.65 & 0.73 & 0.69 & 3.223018 \\
\hline 2 & M2 & 80 & 0.125 & 8 & H 11 & 0.77 & 0.65 & 0.71 & 2.974833 \\
\hline 3 & M2 & 80 & 0.150 & 12 & $\mathrm{HCHCr}$ & 0.99 & 1.13 & 1.06 & -0.50612 \\
\hline 4 & M2 & 160 & 0.10 & 4 & H 11 & 0.98 & 0.60 & 0.79 & 2.047458 \\
\hline 5 & M2 & 160 & 0.125 & 8 & $\mathrm{HCHCr}$ & 0.89 & 0.99 & 0.94 & 0.537443 \\
\hline 6 & M2 & 160 & 0.150 & 12 & EN 31 & 1.10 & 1.06 & 1.08 & 0.66848 \\
\hline 7 & M2 & 244 & 0.10 & 8 & EN 31 & 0.78 & 0.70 & 0.74 & 2.615366 \\
\hline 8 & M2 & 244 & 0.125 & 12 & H 11 & 0.88 & 1.08 & 0.98 & 0.175478 \\
\hline 9 & M2 & 244 & 0.150 & 4 & $\mathrm{HCHCr}$ & 1.15 & 0.81 & 0.98 & 0.175478 \\
\hline 10 & M35 & 80 & 0.10 & 12 & $\mathrm{HCHCr}$ & 1.02 & 1.02 & 1.02 & -0.172 \\
\hline 11 & M35 & 80 & 0.125 & 4 & EN 31 & 0.56 & 0.82 & 0.69 & 3.223018 \\
\hline 12 & M35 & 80 & 0.150 & 8 & $\mathrm{H} 11$ & 0.79 & 0.61 & 0.70 & 3.098039 \\
\hline 13 & M35 & 160 & 0.10 & 8 & $\mathrm{HCHCr}$ & 0.89 & 0.83 & 0.86 & 1.310031 \\
\hline 14 & M35 & 160 & 0.125 & 12 & EN 31 & 0.93 & 0.75 & 0.84 & 1.514414 \\
\hline 15 & M35 & 160 & 0.150 & 4 OIT & H 11 & 0.75 & 0.77 & 0.76 & 2.383728 \\
\hline 16 & M35 & 244 & 0.10 & 12 & esH11 h & 0.84 & 0.96 & 0.90 & 0.91515 \\
\hline 17 & M35 & 244 & 0.125 & 4 & $\mathrm{HCHCr}$ & 0.99 & 1.05 & 1.02 & -0.172 \\
\hline 18 & M35 & 244 & 0.150 & 8 & EN 31 & 0.86 & 0.88 & 0.87 & 1.209615 \\
\hline
\end{tabular}

PROCEDURES OF TAGUCHI METHOD

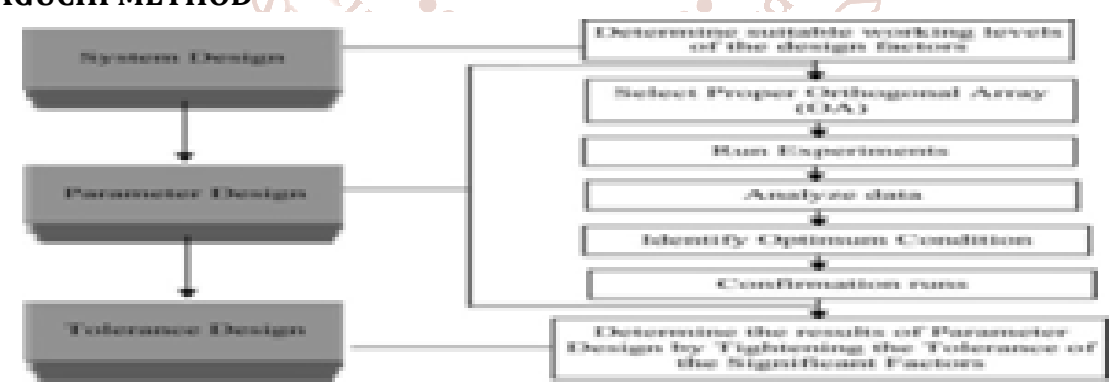

Figure 2- Taguchi design procedure

\section{RESULTS FOR SURFACE ROUGHNESS $\left(\mathrm{R}_{\mathrm{A}}\right)$}

In this study surface roughness of 18 experimental trials with repetition has measured for each sample. For measuring surface roughness, the sampling length is taken as $3 \mathrm{~mm}$ and cut off length is taken as $0.8 \mathrm{~mm}$. The results for surface roughness for each of the 18 experimental trials with repetition are given in Table .

Table4.Analysis Of Variance - Surface Roughness:

\begin{tabular}{|c|c|c|c|c|c|c|c|}
\hline Sources & SS & V & V & F & P & \%contribution & Status \\
\hline Work piece (A) & 11.5405 & 2 & 5.7703 & 30.68 & 0.001 & 33.76 & Significant \\
\hline Feed (B) & 1.5242 & 2 & 0.7621 & 4.05 & 0.077 & & Insignificant \\
\hline Dill diameter (C) & 11.2950 & 2 & 5.6475 & 30.03 & 0.001 & 32.99 & Significant \\
\hline Drill material (D) & 0.4157 & 1 & 0.4157 & 2.21 & 0.188 & & Insignificant \\
\hline Cutting speed (E) & 4.1676 & 2 & 2.0838 & 11.08 & 0.010 & 10.48 & Significant \\
\hline Drill material×Cuttingspeed(F) & 1.5963 & 2 & 0.7981 & 4.24 & 0.071 & 10.02 & Insignificant \\
\hline Residual Error & 1.1285 & 6 & 0.1881 & 3.22 & 0.014 & 9.64 & Insignificant \\
\hline Total & 31.6678 & 1 & & & & 100 & \\
\hline
\end{tabular}


The results were analysed using ANOVA for identifying the significant factors affecting the performance measures. The Analysis of Variance (ANOVA) for the mean surface roughness at 95\% confidence interval is given in Table. The variation data for each factor were F-tested to find significance of each.

The principle of the F-test is that the larger the $\mathrm{F}$ value for a particular parameter, the greater the effect on the performance characteristic due to the change in that process parameter. ANOVA table shows that work piece material with $\mathrm{F}$ value of 26.47 , drill diameter with $\mathrm{F}$ value of 26.61 and cutting speed with F value of 7.74 are the factors that significantly affect the surface roughness.

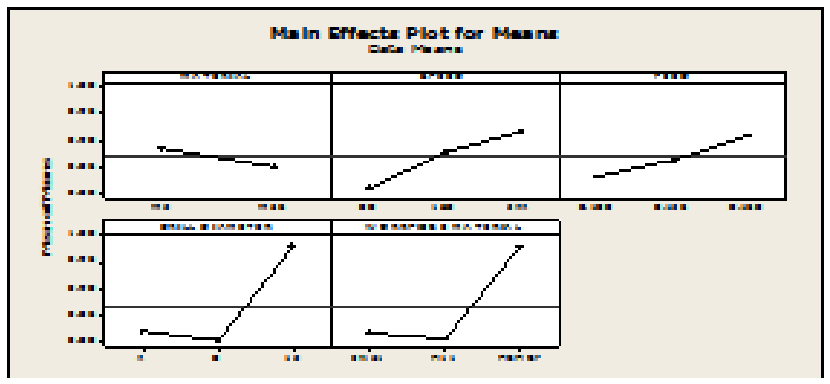

Figure 3: Main effect plot for Mean Surface roughness

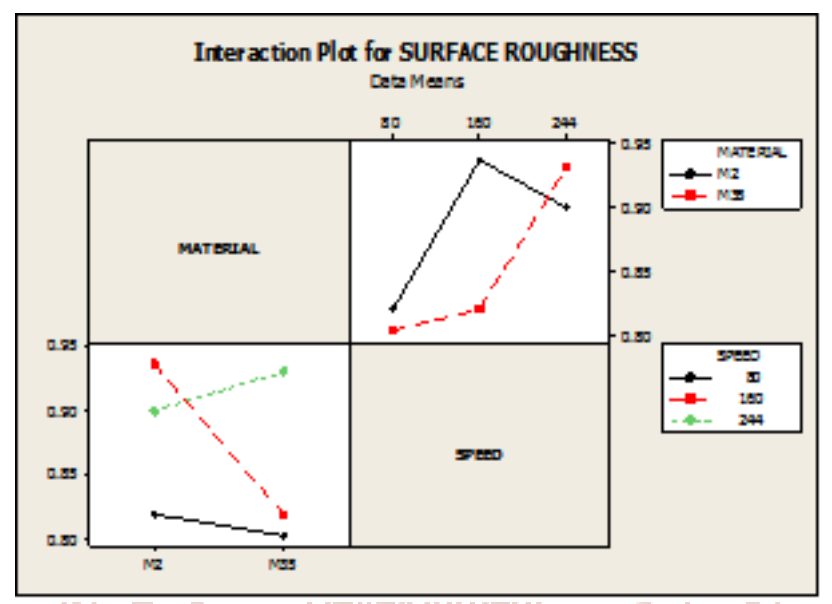

Figure4: Interaction plot for Mean Surface Roughness

\section{RESULTS FOR S/N RATIO - SURFACE ROUGHNESS}

The $\mathrm{S} / \mathrm{N}$ ratio is an indication of the amount of variation present in the process. The $\mathrm{S} / \mathrm{N}$ ratios have been calculated to identify the major contributing factors that cause variation in surface roughness. Surface roughness is a "lower the better" type response and it is given by a logarithmic function based on the mean square deviation:

Table: 5 ANOVA for Surface Roughness

\begin{tabular}{|c|c|c|c|c|c|c|c|}
\hline Sources & SS & V & V & F & P & \%contriButio & Status \\
\hline Work piece (A) & 0.112633 & 2 & 0.056317 & 26.47 & 0.001 & 33.19 & Significant \\
\hline Feed (B) & 0.017100 & 2 & 0.008550 & 4.02 & 0.078 & 31.02 & Insignificant \\
\hline Dill diameter (C) & 0.113233 & 2 & 0.056617 & 26.61 & 0.001 & 33.38 & Significant \\
\hline Drill material (D) & 0.005339 & 1 & 0.005339 & 2.51 & 0.164 & 32.20 & Insignificant \\
\hline Cutting speed(E) & 0.032933 & 2 & 0.016467 & 7.74 & 0.022 & 7.55 & Significant \\
\hline Drillmaterial $\times$ Cutting & 0.016844 & 2 & 0.008422 & 3.96 & 0.080 & 6.23 & Insignificant \\
\hline Residual Error & 0.01276 & 6 & 0.00212 & 3.25 & 0.01 & 6.01 & Insignificant \\
\hline Total & 0.310850 & 17 & 0.00103 & 3.12 & 0.002 & 100 & Insignificant \\
\hline E pooled & 0.05205 & 11 & 0.00473 & & & 25.88 & Insignificant \\
\hline
\end{tabular}

Table:6 Response table for Signal to Noise Ratios of Surface roughness

\begin{tabular}{|c|c|c|c|c|c|c|c|}
\hline Sources & SS & V & V & F & P & \%contriButio & Status \\
\hline Work piece (A) & 0.112633 & 2 & 0.056317 & 26.47 & 0.001 & 33.19 & Significant \\
\hline Feed (B) & 0.017100 & 2 & 0.008550 & 4.02 & 0.078 & 31.02 & Insignificant \\
\hline Dill diameter (C) & 0.113233 & 2 & 0.056617 & 26.61 & 0.001 & 33.38 & Significant \\
\hline Drill material (D) & 0.005339 & 1 & 0.005339 & 2.51 & 0.164 & 32.20 & Insignificant \\
\hline Cutting speed(E) & 0.032933 & 2 & 0.016467 & 7.74 & 0.022 & 7.55 & Significant \\
\hline Drillmaterial $\times$ Cutting & 0.016844 & 2 & 0.008422 & 3.96 & 0.080 & 6.23 & Insignificant \\
\hline Residual Error & 0.01276 & 6 & 0.00212 & 3.25 & 0.01 & 6.01 & Insignificant \\
\hline Total & 0.310850 & 17 & 0.00103 & 3.12 & 0.002 & 100 & Insignificant \\
\hline E pooled & 0.05205 & 11 & 0.00473 & & & 25.88 & Insignificant \\
\hline
\end{tabular}




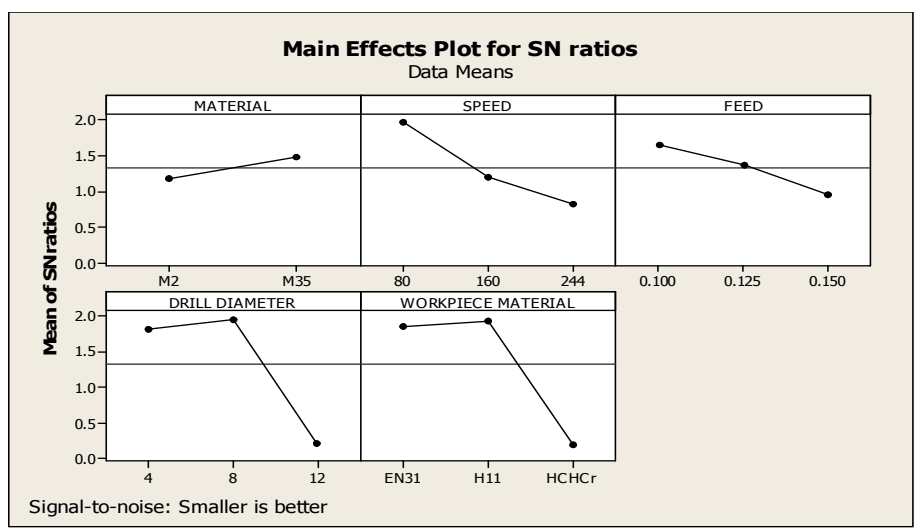

Figure 5: Main effect plot for S/N ratio of Surface Roughness

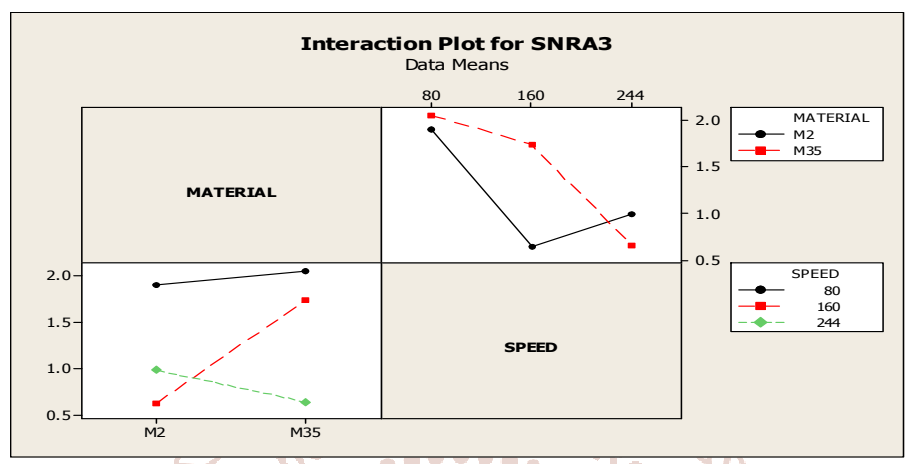

\section{CONCLUSION}

The effect of parameters i.e. cutting speed, feed rate, drill diameters, work piece material, drill material and interaction effect between drill material and cutting speed evaluated using ANOVA design analysis and Regression analysis. The purpose of the ANOVA was to identify the important parameters in prediction of MRR, Surface Roughness. Some results concluded from ANOVA and plots are given below:

\section{Surface Roughness}

The effects of parameters i.e. cutting speed, feed rate, drill diameters, work piece material, drill material and interaction effect between drill material and cutting speed were evaluated using ANOVA analysis. A confidence interval of $95 \%$ has been used for the analysis. One repetition for each of 18 trails was completed to measure the Signal to Noise ratio(S/N Ratio).

In this experiment work surface roughness (Ra) has measured at position center. ANOVA table shows that work piece material with $F$ value 26.47, drill diameter with $F$ value 26.61 and cutting speeds with $F$ value 7.74 are the factors that significantly affect the surface roughness.

The percentage contribution of these factors is $33.19 \%$, $33.38 \%, 7.55 \%$. All others factors, namely, feed, drill material xcutting speed and drill material were found to be insignificant. The estimated mean values of roughness considered with $95 \%$ confidence interval found to be 0.8017 $\pm 0.0667 \mu \mathrm{m}$.
REFERENCES

[1] Palanikumar K., Parkash S. and Shanmugan K., (2008), "Evaluation of delamination in drilling GFRP composites", Materials and Manufacturing process, Vol. 23(8), pp. 858-864.

[2] Taso C. C., (2008, "Prediction of thrust force of step drill in drilling composite material by Taguchi method and radial basis function network", International Journal of Advanced Manufacturing Technology, Vol. 36, pp. 1118.

[3] Palanikumar K., (2010), "Modeling and Analysis of Delamination factor \& surface roughness in drilling GFRP Composites", Materials and Manufacturing Processes, Vol. 25, pp. 1059-1067.

[4] Gaitonde V.N., Karnik S.R., Rubio J., A. Correia E., Abra A.M. and Davim J., (2008),"Analysis of parametric influence on delamination in high-speed drilling of carbon fibre reinforced plastic composites", Journal of Materials Processing Technology, Vol. 203, pp. 31-438.

[5] Tsao C.C. and ocheng ., (2007, "Effect of tool wear on delamination in drilling composite materials", International Journal of Mechanical Sciences, Vol. 9, pp. 983-988.

[6] Hochenga H. and Tsao C.C., (2006, "Effects of special drill bits on drilling-induced delamination of composite materials", International Journal of Machine Tools \& Manufacture, Vol. 46, pp. 1403-1416. 